\title{
Formulation and Evaluation of Compression Coated Tablets of Lornoxicam for Targeting Early Morning Peak Symptoms of Rheumatoid Arthritis
}

\author{
Mohd Abdul Hadi ${ }^{1}$, N. G. Raghavendra Rao ${ }^{2}$ and A. Srinivasa Rao ${ }^{3}$ \\ ${ }^{1}$ Department of Pharmaceutics, Bhaskar Pharmacy College (JB Group of Educational Institutions) \\ Yenkapally (V), Moinabad (M), R.R.District, Hyderabad-500075, Andhra Pradesh, India \\ ${ }^{2}$ Jyothishmathi Institute of Pharmaceutical Science, Ramakrishna colony, Thimmapur, Karimnagar -505481 \\ Andhra Pradesh, India \\ ${ }^{3}$ Bhaskar Pharmacy College (JB Group of Educational Institutions), Yenkapally (V), Moinabad (M) \\ R.R.District, Hyderabad-500075, Andhra Pradesh, India
}

\begin{abstract}
In the present research work, we have designed a pulsatile formulation of lornoxicam to treat rheumatoid arthritis as per the chronotherapeutic pattern of the disease. Core tablets were prepared by incorporating different concentration of disintegrants and were compressed in between different concentration and combination of hydrophobic and hydrophilic polymers. The core and compression coated tablets were subjected to pre-formulation, physicochemical, in-vitro drug release and stability studies. FTIR and DSC studies revealed that there was not any chemical reaction between pure drug lornoxicam and polymers. The pre and post-compressional parameters of tablets were also found to be within limits. The core tablets which were incorporated with $10 \%$ of crospovidone were found to be as most fastly disintegrating. Our optimized formulation F-5 releases lornoxicam after a lag time of $5.5 \pm 0.7$ hours and $99.81 \pm 0.81 \%$ upto 8 hours. Stability was also found for the optimized formulation according to ICH guidelines.
\end{abstract}

Key words: Pulsatile formulation, Lornoxicam, Rheumatoid arthritis, Chronotherapeutic pattern, Compression coated tablets.

\section{INTRODUCTION}

Rheumatoid arthritis is a chronic disease and it destroys the joints intergrity. In patients of rheumatoid arthritis, symptoms such as pain in the joints and functional disability mainly persists in the early morning time after awakening. ${ }^{1}$ It has been recommended to treat rheumatoid arthritis by using the concept of chronopharmacotherapy to ensure that the highest blood levels of the drug should be available to treat the peak pain and stiffness. A pulsatile drug delivery system which can be administered at night i.e. before sleep but releases the drug during early morning time would be a promising chronopharmaceutic system. ${ }^{2,3}$ These type of delivery

Correspondence to: Mohd Abdul Hadi,

Mob No: +91-9949444787

E-mail: hadi.lcp@gmail.com

Dhaka Univ. J. Pharm. Sci. 12(2): 109-117, 2013 (December) systems deliver the drug at the time when the symptoms of the disease are at its peak within a period of 24 hours. They rapidly release the drug after a lag time (i.e. a period of no drug release). ${ }^{4}$

Drug targeting to the colon has been found as a useful approach for delaying the drug absorption, and it usually requires for the treatment of diseases that are having symptoms in the early morning time like rheumatoid arthritis. ${ }^{5,6}$ Compression coated tablets are one such delivery systems through which drugs can be easily targeted to the colon. ${ }^{7}$

Lornoxicam belongs to the class of NSAIDs and is more effective for treating the pain and inflammation of rheumatoid arthritis. ${ }^{8,9}$

By keeping in view to target lornoxicam during the time of its greatest need in rheumatoid arthritis, 
we have developed compression coated tablets of lornoxicam as a pulsatile drug delivery system.

\section{MATERIALS AND METHODS}

Materials. Lornoxicam and L-hpc were received as a gift sample from Spectrum Pharma Training Institute, Hyderabad, India. Ethyl cellulose, HPMC K4M and PVP K30 were obtained from FMC Biopolymers. Sodium carboxy methyl cellulose, Lactose, Avicel PH 102 and Aerosil was purchased from SD Fine Chemicals, Mumbai. Magnesium stearate was purchased from Himedia Chem Lab, Mumbai. The remaining ingredients were of analytical grade.

\section{Preformulation studies}

Fourier Transform Infrared (FTIR) spectral analysis. ${ }^{10}$ Compatibility studies were carried out between pure drug lornoxicam and polymers used in the formulation. We used $2 \mathrm{mg}$ of sample in $200 \mathrm{mg}$ of potassium bromide pellets (Perkin Elmer, Spectrum-100, Japan). The range of scanning was 400 to $4000 \mathrm{~cm}^{-1}$ and the resolution was $1 \mathrm{~cm}^{-1}$.

DSC studies. ${ }^{10}$ DSC thermograms of pure drug lornoxicam and physical mixture of drug and polymers used in the formulation were recorded using Diffraction scanning calorimeter (Shimadzu, Japan). We performed the measurement between 30 and $350^{\circ} \mathrm{C}$ at heating rate of $10^{\circ} \mathrm{C} / \mathrm{min}$.

\section{Experimental methods}

Preparation of core tablets of lornoxicam. ${ }^{11}$ Direct compression technique was used to prepare the core tablets of lornoxicam. As per the quantity mentioned in Table 1, lornoxicam, crospovidone, lactose and PVP K30 were weighed and passed through a sieve of 60 mesh size. This mixture after thoroughly blending in a mortar was lubricated with magnesium stearate and aerosil and further blended for 10 minutes. This prepared blend was finally punched into core tablets using $8 \mathrm{~mm}$ flat faced punches on a rotary tablet press (Rimek minipress, Karnavathi engineering, Ahmedabad).

Table 1. Formulation of core tablets.

\begin{tabular}{lcccc}
\hline \multirow{2}{*}{ Ingredients } & \multicolumn{4}{c}{ Quantity $(\mathrm{mg})$} \\
\cline { 2 - 5 } & LCT-1 & LCT-2 & LCT-3 & LCT-4 \\
\hline Lornoxicam & 8 & 8 & 8 & 8 \\
Crospovidone & 0 & 2.5 & 5 & 10 \\
PVP K30 & 5 & 5 & 5 & 5 \\
Lactose & 85.4 & 82.9 & 80.4 & 75.4 \\
Aerosil & 0.8 & 0.8 & 0.8 & 0.8 \\
Magnesium & 0.8 & 0.8 & 0.8 & 0.8 \\
stearate & & & & \\
Total weight & 100 & 100 & 100 & 100 \\
\hline
\end{tabular}

LCT: Lornoxicam core tablets

Preparation of compression-coated tablets. ${ }^{11}$

The prepared core tablets of lornoxicam were further compression coated with polymers of different weight ratios as shown in Table 2. First, a powder bed at the bottom of the die cavity was made by

Table 2. Formulations of compression coated tablets of lornoxicam.

\begin{tabular}{|c|c|c|c|c|c|c|c|c|c|c|c|c|}
\hline Ingredients & $\begin{array}{l}\mathrm{F}-1 \\
(\mathrm{mg})\end{array}$ & $\begin{array}{l}\text { F-2 } \\
(\mathrm{mg})\end{array}$ & $\begin{array}{l}\text { F-3 } \\
(\mathrm{mg})\end{array}$ & $\begin{array}{l}\text { F-4 } \\
(\mathrm{mg})\end{array}$ & $\begin{array}{l}\text { F-5 } \\
(\mathrm{mg})\end{array}$ & $\begin{array}{l}\text { F-6 } \\
(\mathrm{mg})\end{array}$ & $\begin{array}{l}\text { F-7 } \\
(\mathrm{mg})\end{array}$ & $\begin{array}{l}\text { F-8 } \\
(\mathrm{mg})\end{array}$ & $\begin{array}{l}\text { F-9 } \\
(\mathrm{mg})\end{array}$ & $\begin{array}{l}\text { F-10 } \\
(\mathrm{mg})\end{array}$ & $\begin{array}{l}\text { F-11 } \\
(\mathrm{mg})\end{array}$ & $\begin{array}{l}\text { F-12 } \\
(\mathrm{mg})\end{array}$ \\
\hline $\begin{array}{l}\text { Lornoxicam } \\
\text { core tablet (LCT-4) }\end{array}$ & 100 & 100 & 100 & 100 & 100 & 100 & 100 & 100 & 100 & 100 & 100 & 100 \\
\hline \multicolumn{13}{|c|}{ Composition of Barrier layers } \\
\hline HPMC K4M & 150 & 200 & 225 & 240 & -- & -- & -- & -- & - & -- & -- & -- \\
\hline L-hpc & -- & -- & -- & -- & 150 & 200 & 225 & 240 & -- & -- & -- & -- \\
\hline $\mathrm{NaCMC}$ & -- & -- & -- & -- & -- & -- & -- & -- & 150 & 200 & 225 & 240 \\
\hline EC (18-22 cps) & 150 & 100 & 75 & 60 & 150 & 100 & 75 & 60 & 150 & 100 & 75 & 60 \\
\hline Total coating weight & 300 & 300 & 300 & 300 & 300 & 300 & 300 & 300 & 300 & 300 & 300 & 300 \\
\hline $\begin{array}{l}\text { Final compression } \\
\text { coated tablets } \\
\text { weight }\end{array}$ & 400 & 400 & 400 & 400 & 400 & 400 & 400 & 400 & 400 & 400 & 400 & 400 \\
\hline
\end{tabular}

HPMC- Hydroxypropylmethyl cellulose; L-hpc- Low substituted hydroxypropyl cellulose; NaCMC: Sodium carboxymethyl cellulose; EC- Ethyl cellulose. 
filling the half quantity of coating polymer blend. Then, the previously prepared core tablets of lornoxicam was placed in the centre of the above powder bed and filled with the remaining half quantity of coating polymer blend in the upper portion of the die. Finally, the whole content was compressed using $11 \mathrm{~mm}$ concave punches.

\section{Evaluation parameters}

Pre-compression parameters. ${ }^{12}$ The prepared powder blend for core tablets was evaluated for various pre-compression parameters like angle of repose, bulk and tapped density, Carr's compressibility index and Hausner's ratio.

Post-compression parameters. ${ }^{12}$ The prepared core tablets and compression coated tablets were evaluated for post-compression parameters such as hardness, thickness, weight variation, friability etc.

In vitro disintegration time. ${ }^{13}$ The in-vitro disintegration of the core tablets were determined using disintegration test apparatus as per I.P specifications. One core tablet was placed into each of the six tubes of the basket. The disc was added to each tube and run the apparatus using $900 \mathrm{ml}$ of $\mathrm{pH}$ 6.8 phosphate buffer as the immersion liquid. The assembly should be raised and lowered between 30 cycles per minute maintained at $37^{\circ} \mathrm{C}$. The time in seconds for complete disintegration of the core tablets with no palable mass remaining in the apparatus was measured and recorded.

Drug Content Uniformity. ${ }^{\mathbf{1 0}} 10$ core tablets of lornoxicam were crushed into a fine powder in mortar, and the weighed powder equivalent to $8 \mathrm{mg}$ of lornoxicam was extracted in $\mathrm{pH} 6.8$ phosphate buffer. Then filter the solution through a millpore filter of 0.45 pore size. Finally, drug content was determined by UV-spectrophotometer (UV-1700, Shimadzu corporation, Japan) at a $\lambda_{\max } 375 \mathrm{~nm}$ after suitable dilution.

In vitro dissolution testing of core tablets and compression coated tablets of lornoxicam. ${ }^{10} \mathrm{We}$ performed the dissolution studies using USP XXIII dissolution test apparatus paddle type (Electrolab USP, India) by maintaining a rotation speed of 100 rpm at $37 \pm 0.5^{\circ} \mathrm{C}$. First, core tablets of lornoxicam were subjected to dissolution testing in order to assess the effect of disintigrant. This study was carried out by using $900 \mathrm{ml}$ of $\mathrm{pH} 6.8$ phosphate buffer. Then, the compression coated tablets of lornoxicam were also subjected to dissolution testing in order to assess the effect of different weight ratios of coating polymer blend. This study was carried out by using $750 \mathrm{ml}$ of $\mathrm{pH} 1.2$ buffer for 2 hours and further continued with $900 \mathrm{ml}$ of $\mathrm{pH} 6.8$ phosphate buffer for remaining subsequent hours. At equal intervals of time, $5 \mathrm{ml}$ of sample was withdrawn from the dissolution medium and was replaced with equal volume of $\mathrm{pH} 1.2$ and $\mathrm{pH} 6.8$ buffers respectively. After filtering the samples through Whatman filter paper the amount of lornoxicam released was analyzed using a shimadzu UV-Spectrophotometer at a $\lambda_{\max } 376$ and $375 \mathrm{~nm}$ for samples tested in $\mathrm{pH} 1.2$ and $\mathrm{pH} 6.8$ buffers, respectively.

Stability studies. ${ }^{14}$ The stability studies were performed by packing the optimized formulation in an amber colored glass container which was closed tightly with a screw cap. Then the container was exposed to $40^{\circ} \mathrm{C} \pm 2^{\circ} \mathrm{C} / 75 \% \pm 5 \% \mathrm{RH}$ in a stability chamber according to $\mathrm{ICH}$ guidelines for a period of 6 months. The containers were removed at regular intervals of time and the tablets were again subjected to evaluation of parameters like appearance, drug content, hardness and dissolution profile.

Statistical analysis. Statistical analysis was expressed as mean \pm standard deviation and the experimental tests were performed for a repeated number of times which control the experimental wise error at rate $\alpha=0.05$ which was used to determine significance among all possible pairs of formulations and interactions. The level of statistical significance was chosen as $\mathrm{p} \leq 0.05$.

\section{RESULTS AND DISCUSSION}

In this research work, our main was to target lornoxicam as per the circadian rhythm of rheumatoid arthritis. As the symptoms of this disease mainly persists in the early morning hours, by keeping this 
fact in view we aimed to design a pulsatile dosage form. The desired lornoxicam release profile was targeted in such a way that when the formulation is taken before going to bed, then maximum portion of the drug should be released in the early morning hours so that, maximum portion of the drug will be available for targeting early morning peak symptoms of rheumatoid arthritis.

In our research work, the designed tablet device is based on time dependent drug delivery approach. The device was formulated into two steps: First lornoxicam was prepared as fast dissolving core tablets; second these was core tablets of lornoxicam pressed on a bigger die in between the coating polymer blend.

FTIR studies. Spectra of pure drug Lornoxicam, polymers and physical mixture of both drug and polymer in compression coated tablets was recorded in between 400 to $4000 \mathrm{~cm}^{-1}$.

The following results were obtained after FTIR spectral analysis:

Lornoxicam. Ar-CH: $3100 \mathrm{~cm}^{-1}$, $-\mathrm{NH}: 3066$ $\mathrm{cm}^{-1},-\mathrm{C}=\mathrm{O}: 1647 \mathrm{~cm}^{-1},-\mathrm{CONH}-: 1594 \mathrm{~cm}^{-1},-\mathrm{SO}_{2}$ : $1327 \mathrm{~cm}^{-1}, \mathrm{C}-\mathrm{Cl}: 790 \mathrm{~cm}^{-1}$.

Low substituted hydroxyl propyl cellulose. OH: $3418 \mathrm{~cm}^{-1}$, CH: $2886 \mathrm{~cm}^{-1}$, C-O: $1317 \mathrm{~cm}^{-1}$.

Ethyl cellulose: $\mathrm{OH}: 3318 \mathrm{~cm}^{-1}$, $\mathrm{CH}: 2911 \mathrm{~cm}^{-1}$.

Lornoxicam + Low substituted hydroxyl propyl cellulose + ethyl cellulose. $\mathrm{OH}: 3400 \mathrm{~cm}^{-1}$, -NH: $3288 \mathrm{~cm}^{-1}$, Ar-CH: $2972 \mathrm{~cm}^{-1}$, CH: $2902 \mathrm{~cm}^{-1}$, $-\mathrm{C}=\mathrm{O}: 1749 \mathrm{~cm}^{-1}$, -CONH-: $1647 \mathrm{~cm}^{-1},-\mathrm{SO} 2: 1387$ $\mathrm{cm}^{-1}$, C-O: $1080 \mathrm{~cm}^{-1}, \mathrm{C}-\mathrm{Cl}: 785 \mathrm{~cm}^{-1}$.

The recorded spectra (as shown in figure 1) reveal that all the peaks which are present in drug and polymers remained intact in their physical mixture.

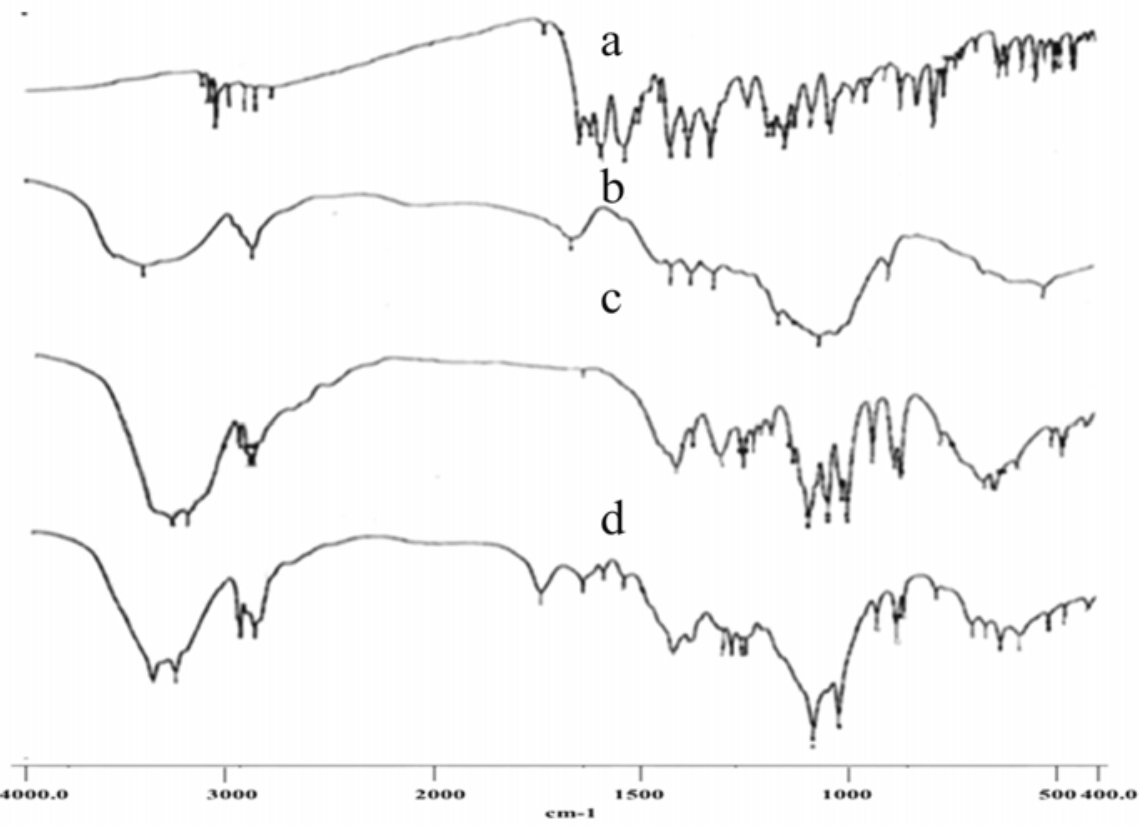

Figure 1. FTIR spectra of a) Pure drug lornoxicam b) Low substituted hydroxyl propyl cellulose (L-hpc) c) Ethyl cellulose d) Lornoxicam + L-hpc + ethyl cellulose.

DSC studies. Along with FTIR studies, DSC thermograms were also taken to study the compatibility between drug and polymers. The DSC thermograms of drug, and physical mixture of drug and polymers is shown in Figure 2. DSC thermograms of lornoxicam due to its melting process shown a sharp endothermic peak at $218.74^{\circ} \mathrm{C}$. The peak for physical mixture of lornoxicam, low substituted hydroxyl propyl cellulose and ethyl cellulose in Formulation F-5 was found at $219.79{ }^{\circ} \mathrm{C}$. 
The same range of drug melting peak is present even in the physical mixture of formulations. Thus, both the FTIR and DSC studies confirms that there was no possible chemical interaction between pure drug lornoxicam and polymers which are present in the optimized formulation F-5.

Evaluation of powder blend. The angle of repose values for all the core tablets was found to range between $22^{\circ} .15^{\prime} \pm 0.13$ to $24^{\circ} .40^{\prime} \pm 0.10$, which were less than 30 and hence indicates good
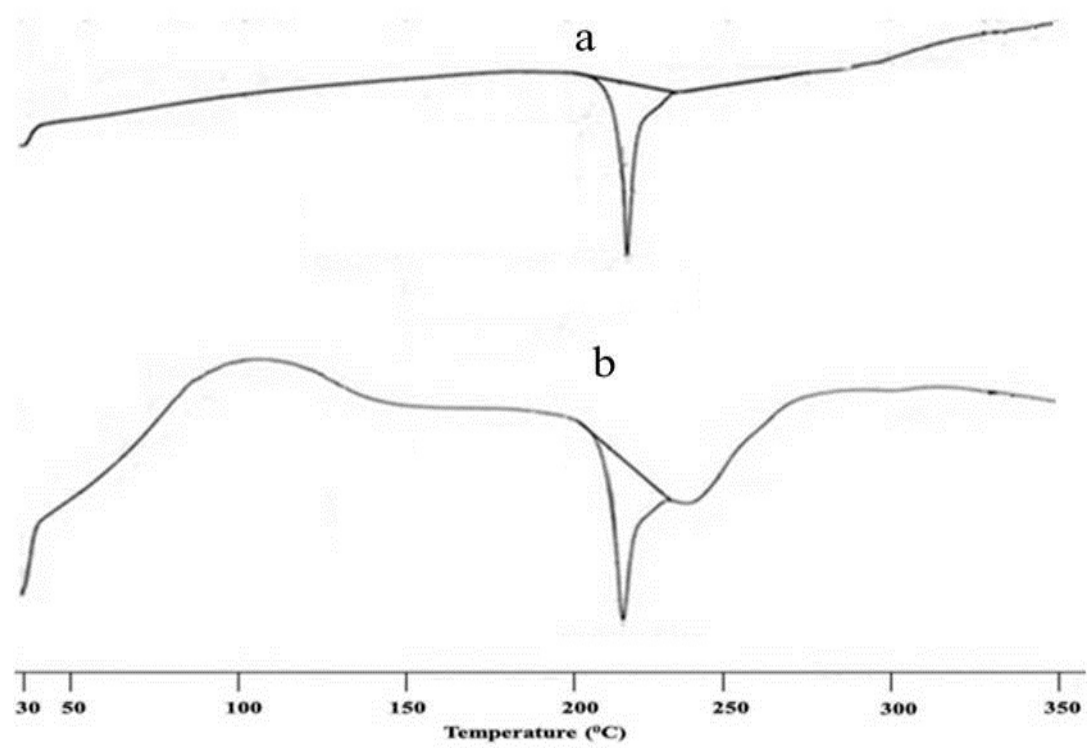

Figure 2. DSC spectra of a) Pure drug lornoxicam b) Lornoxicam + Low substituted hydroxyl propyl cellulose + Ethylcellulose.

Table 3. Results of physical evaluation of Pre-compression Blend.

\begin{tabular}{cccccc}
\hline Batches & $\begin{array}{c}\text { Angle of repose }\left(^{\circ}\right) \\
\pm \mathrm{SD}, \mathrm{n}=3\end{array}$ & $\begin{array}{c}\text { Bulk density } \\
(\mathrm{gm} / \mathrm{cc}) \\
+\mathrm{SD} \mathrm{n}=3\end{array}$ & $\begin{array}{c}\text { Tapped density }(\mathrm{gm} / \mathrm{cc}) \\
\pm \mathrm{SD}, \mathrm{n}=3\end{array}$ & $\begin{array}{c}\text { Carr's index (\%) } \\
\pm \mathrm{SD}, \mathrm{n}=3\end{array}$ & $\begin{array}{c}\text { Hausner's ratio } \\
\pm \mathrm{SD}, \mathrm{n}=3\end{array}$ \\
\hline LCT-1 & $24^{\circ} .40^{\prime} \pm 0.14$ & $0.59 \pm 0.02$ & $0.69 \pm 0.02$ & $14.49 \pm 0.94$ & $1.16 \pm 0.02$ \\
LCT-2 & $22^{\circ} .48^{\prime} \pm 0.09$ & $0.57 \pm 0.02$ & $0.66 \pm 0.02$ & $13.63 \pm 0.81$ & $1.15 \pm 0.01$ \\
LCT-3 & $23^{\circ} .36^{\prime} \pm 0.10$ & $0.58 \pm 0.01$ & $0.67 \pm 0.02$ & $13.43 \pm 0.90$ & $1.15 \pm 0.02$ \\
LCT-4 & $22^{\circ} .15^{\prime} \pm 0.13$ & $0.59 \pm 0.03$ & $0.68 \pm 0.03$ & $13.23 \pm 0.86$ & $1.15 \pm 0.03$ \\
\hline
\end{tabular}

Evaluation of prepared core tablets. The physical evaluation results of core-tablets are given in Table 4. The hardness of all the core tablet batches was found to range between $3.69 \pm 0.10$ to $3.77 \pm 0.16$ $\mathrm{kg} / \mathrm{cm}^{2}$. Friability values were also found to be less than 1. Thus, the results of hardness and friability values have shown that core tablets have got sufficient strength. The thickness was found to range between $2.14 \pm 0.01$ to $2.16 \pm 0.01 \mathrm{~mm}$. The results flow properties of the powder. The compressibility index values for all the core tablets was found to range between $13.23 \pm 0.86$ to $14.49 \pm 0.94$, which were less than $15 \%$ and hence results in good to excellent flow properties. The Hausner's ratio values were also lesser than 1.25 which indicates good flow properties. Thus, the prepared powder blend for all the core tablets was exhibiting good flow properties as evident from Table 3 . 
subjected to disintegration studies it was found that as the concentration of crospovidone was increasing the disintegration time was decreased. The disintegration time was found to range between $1.52 \pm 0.47$ to $12.44 \pm 0.35$ and LCT- 4 batch was found to be the most fast disintegrating core tablets.

In vitro dissolution testing of core tablets tablets of lornoxicam. The results of In-vitro dissolution testing for LCT-1, LCT-2, LCT-3 and LCT-4 core tablets showed that they released
$53.66 \pm 0.91,62.01 \pm 1.05,69.16 \pm 0.84$ and $99.93 \pm 0.81$ $\%$ of lornoxicam at the end of 30 minutes. From the results we found, as the concentration of crospovidone in core tablets was increasing, the release of lornoxicam was also increased in 30 minutes period of time as shown in Figure 3. Hence, we considered LCT-4 batch core tablets to be the most suitable for incorporation in compression coated tablets.

Table 4. Evaluation of core tablets of lornoxicam.

\begin{tabular}{ccccccc}
\hline $\begin{array}{c}\text { Core- } \\
\text { tablets } \\
\text { batch }\end{array}$ & $\begin{array}{c}\text { Weight variation(mg) } \\
( \pm \mathrm{SD}), \mathrm{n}=20\end{array}$ & $\begin{array}{c}\text { Hardness } \\
\left(\mathrm{kg} / \mathrm{cm}^{2}\right) \\
( \pm \mathrm{SD}), \mathrm{n}=6\end{array}$ & $\begin{array}{c}\text { Thickness } \\
(\mathrm{mm}) \\
( \pm \mathrm{SD}), \mathrm{n}=10\end{array}$ & $\begin{array}{c}\text { Friability } \\
(\%) \\
( \pm \mathrm{SD}), \mathrm{n}=6\end{array}$ & $\begin{array}{c}\text { \% Drug } \\
\text { content } \\
( \pm \mathrm{SD}), \mathrm{n}=3\end{array}$ & $\begin{array}{c}\text { Disintegration time } \\
(\mathrm{min}) \\
( \pm \mathrm{SD}), \mathrm{n}=3\end{array}$ \\
\hline LCT-1 & $99.4 \pm 0.22$ & $3.89 \pm 0.10$ & $2.14 \pm 0.01$ & $0.16 \pm 0.04$ & $97.63 \pm 0.02$ & $12.44 \pm 0.35$ \\
LCT-2 & $100.6 \pm 0.16$ & $3.94 \pm 0.32$ & $2.16 \pm 0.01$ & $0.24 \pm 0.07$ & $99.12 \pm 0.04$ & $6.74 \pm 0.27$ \\
LCT-3 & $98.0 \pm 0.26$ & $3.90 \pm 0.29$ & $2.15 \pm 0.01$ & $0.19 \pm 0.02$ & $98.10 \pm 0.03$ & $4.96 \pm 0.33$ \\
LCT-4 & $99.8 \pm 0.17$ & $3.97 \pm 0.16$ & $2.16 \pm 0.02$ & $0.11 \pm 0.04$ & $98.22 \pm 0.02$ & $1.52 \pm 0.47$ \\
\hline
\end{tabular}

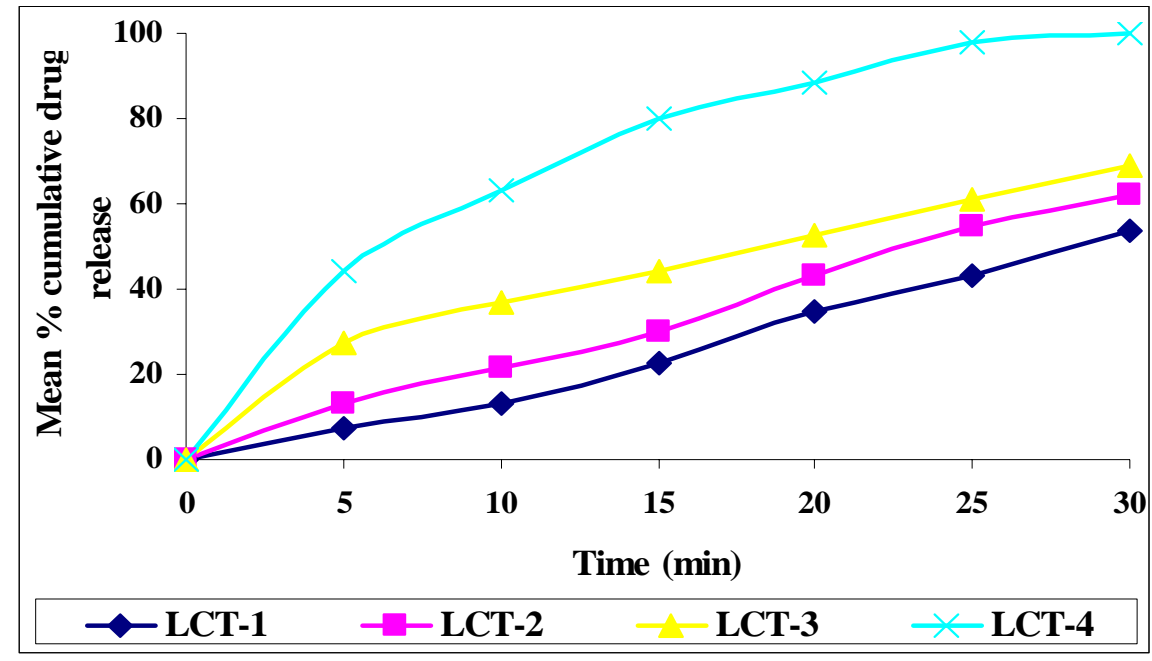

Figure 3, In-vitro release profile of lornoxicam core tablets.

Evaluation of press-coated tablets of lornoxicam. The physical evaluation results of all the press-coated tablets are shown in Table 5. The hardness of all the press coated tablet formulations was found to range between $11.25 \pm 0.18$ to $11.69 \pm 0.28 \mathrm{~kg} / \mathrm{cm}^{2}$. Friability values were also found to be less than 1 . Thus, the results of hardness and friability values have shown that all the compression coated tablet formulations have got sufficient strength. The thickness was found to range between
$4.27 \pm 0.01$ to $4.30 \pm 0.02$. The results of weight variation was found to range between $396 \pm 0.20$ to $404 \pm 0.18$. The weight variation between the compression coated tablets were also found to be in pharmacopoeial limit i.e. $324 \mathrm{mg}$ or more is $\pm 5 \%$.

In vitro dissolution testing of compression coated tablets of lornoxicam. The prepared compression coated tablets of lornoxicam with different combinations and concentrations of HPMC$\mathrm{K} 4 \mathrm{M}$, ethylcellulose and L-HPC, ethylcellulose were 
also subjected to in vitro dissolution testing. Our main aim in the dissolution test was to identify a suitable formulation which could release the drug after a lag time of at least 5 hours and almost all portion of the drug till 8 hours. The results of in vitro dissolution testing profile is shown in figure 4.

When formulations F-1, F-2, F-3 and F-4 prepared with varying concentrations of HPMC-K4M and ethyl cellulose were evaluated it was found that they released lornoxicam after a lag time of $10.5 \pm$ $0.78,8 \pm 0.65,7 \pm 0.93,5.5 \pm 0.82$ hours and $98.38 \pm$ $0.98,98.26 \pm 1.06,99.10 \pm 1.02,99.34 \pm 0.80 \%$ at the end of 14, 12, 11, 9 hours respectively. From these results, it was found that as the concentration of HPMC K4M polymer was increasing or ethylcellulose concentration was decreasing the lag time and dissolution rate of lornoxicam was decreased. This is due to the hydrophilic nature of HPMC K4M polymer. Its rate of hydration has increased due to its increased concentration resulting in increased dissolution rate. All these four formulations do not meet our desired criteria to release lornoxicam.

Table 5. Evaluation of compression coated tablets of lornoxicam.

\begin{tabular}{ccccc}
\hline $\begin{array}{c}\text { Compression-coated } \\
\text { tablets formulations }\end{array}$ & $\begin{array}{c}\text { Weight variation }(\mathrm{mg}) \\
( \pm \mathrm{SD}), \mathrm{n}=20\end{array}$ & $\begin{array}{c}\text { Hardness }\left(\mathrm{kg} / \mathrm{cm}^{2}\right) \\
( \pm \mathrm{SD}), \mathrm{n}=6\end{array}$ & $\begin{array}{c}\text { Thickness }(\mathrm{mm}) \\
( \pm \mathrm{SD}), \mathrm{n}=10\end{array}$ & $\begin{array}{c}\text { Friability }(\%) \\
( \pm \mathrm{SD}), \mathrm{n}=6\end{array}$ \\
\hline F-1 & $396 \pm 0.20$ & $11.57 \pm 0.12$ & $4.27 \pm 0.01$ & $0.25 \pm 0.05$ \\
F-2 & $397 \pm 0.16$ & $11.68 \pm 0.00$ & $4.31 \pm 0.02$ & $0.18 \pm 0.02$ \\
F-3 & $401 \pm 0.19$ & $11.65 \pm 0.32$ & $4.29 \pm 0.03$ & $0.33 \pm 0.06$ \\
F-4 & $398 \pm 0.33$ & $11.69 \pm 0.28$ & $4.28 \pm 0.01$ & $0.18 \pm 0.03$ \\
F-5 & $397 \pm 0.31$ & $11.25 \pm 0.18$ & $4.30 \pm 0.02$ & $0.49 \pm 0.05$ \\
F-6 & $403 \pm 0.29$ & $11.37 \pm 0.00$ & $4.29 \pm 0.01$ & $0.52 \pm 0.04$ \\
F-7 & $399 \pm 0.34$ & $11.41 \pm 0.20$ & $4.29 \pm 0.02$ & $0.38 \pm 0.03$ \\
F-8 & $404 \pm 0.18$ & $11.39 \pm 0.12$ & $4.28 \pm 0.01$ & $0.27 \pm 0.04$ \\
F-9 & $399 \pm 0.20$ & $11.45 \pm 0.26$ & $4.29 \pm 0.02$ & $0.38 \pm 0.05$ \\
F-10 & $398 \pm 0.15$ & $11.42 \pm 0.32$ & $4.30 \pm 0.02$ & $0.36 \pm 0.04$ \\
F-11 & $402 \pm 0.36$ & $11.38 \pm 0.00$ & $4.28 \pm 0.02$ & $0.44 \pm 0.03$ \\
F-12 & $399 \pm 0.19$ & $11.47 \pm 0.22$ & $4.29 \pm 0.01$ & $0.32 \pm 0.04$ \\
\hline
\end{tabular}

When formulations F-5, F-6, F-7 and F-8 prepared with varying concentrations of L-hpc and ethyl cellulose were evaluated it was found that they released lornoxicam after a lag time of $5.5 \pm 0.7,4 \pm$ $0.89,3 \pm 0.76,1.5 \pm 0.88$ hours and $99.81 \pm 0.81$, $99.58 \pm 0.75,99.22 \pm 0.93,99.46 \pm 0.98 \%$ at the end of $8,7,6,4$ hours, respectively. From these results, it was found that as the concentration of L-hpc polymer was increasing or ethyl cellulose concentration was decreasing the lag time and dissolution rate of lornoxicam was decreased. It is due to the reason that L-HPC is hydrophilic in nature and it acts as a disintegrant too. In our formulations as the concentration of L-HPC was increased it leads to the increased wetting and disintegrating tendency of tablet due to its hydrophilic and disintegrant properties and decreases the dissolution time. Similarly, when the concentration of ethylcellulose was more it retarded the wetting of L-HPC polymer due to its hydrophobic tendency and thus decreased the dissolution time.

When formulations F-9, F-10, F-11 and F-12 prepared with varying concentrations of $\mathrm{NaCMC}$ and ethyl cellulose were evaluated it was found that they released lornoxicam after a lag time of $4 \pm 0.88,3 \pm$ $0.95,2 \pm 0.82,1.5 \pm 0.91$ hours and $99.81 \pm 0.77,99.69$ $\pm 0.83,99.93 \pm 0.69,99.46 \pm 0.97 \%$ at the end of 7 , 6, 5, 4 hours, respectively. From these results, it was found that as the concentration of $\mathrm{NaCMC}$ polymer was increasing the lag time and dissolution time of lornoxicam was decreased. Because, as we increased $\mathrm{NaCMC}$ concentration similarly hydrophobic polymer i.e. ethyl cellulose concentration was decreased. It was also found that, while compared to HPMC-K4M and L-HPC polymers this polymer showed a minimal lag time and dissolution time. Therefore, these formulations i.e. from F-8 to F-12 released lornoxicam within a short period of time. 
From all the observations of these formulations, it was found that the order of extending the lag time for polymers was found as HPMC-K4M > L-HPC $>\mathrm{NaCMC}$. Also, it was found that formulation F-5 was the most suitable formulation as it was satisfying our desired criteria. Hence, it was considered as the best formulation.

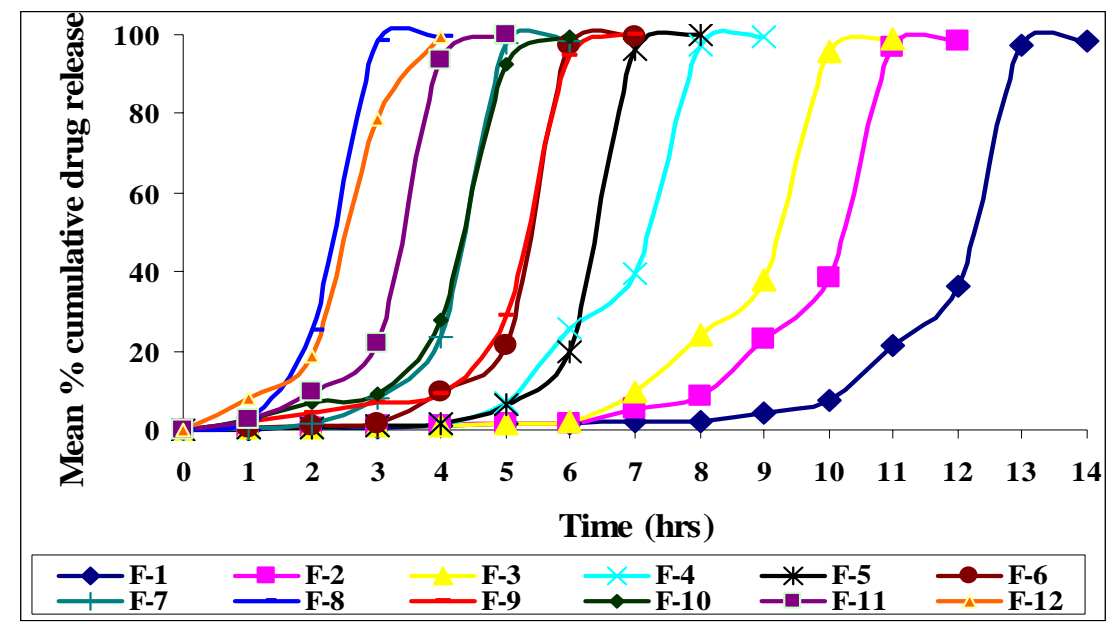

Figure 4. In-vitro release profile of compression coated tablets of lornoxicam.

Stability studies. When optimized compression coated tablets formulation F-5 was subjected for evaluation, it was found that there was no change in appearance and the hardness was also found to be uniform. When performing the stability studies for drug content, it was found that the drug was reduced by $0.87 \%$ (i.e. less than $1 \%$ ) in a period of 6 months indicating the stability of drug. When stability studies were performed for dissolution testing it was observed that there was very small variation (i.e less than $1 \%$ ) in both lag time and drug release profile. The results of in-vitro drug release profile after stability studies were found as $8.27 \pm 1.15$ and $98.93 \pm 1.08$ at the end of 5.5 and 8 hours, respectively. Hence, by the above mentioned results it was confirmed that our optimized formulation was stable for a period of 6 months i.e. according to ICH guidelines.

\section{CONCLUSION}

As we have mentioned in the introduction that our aim was to target lornoxicam in the early morning hours i.e. as per chronotherapy. By keeping this concept in view we have successfully developed a pulsatile dosage form by compression coating of lornoxicam core tablets by combination of L-hpc and ethycellulose polymers. Formulation F-5 was considered as the best formulation as it releases 9.13 \pm 0.79 and $99.81 \pm 0.81 \%$ of lornoxicam at the end of 5.5 and 8 hours, respectively. This release profile is based on the assumption that if the patient takes this optimized formulation at 10:00 A.M (i.e. before going to bed) then the drug starts releasing after a lag time 5.5 hours and almost all portion of the drug will be released in between 4-6 A.M. Thus, maximum drug will be available for targeting early morning peak symptoms of rheumatoid arthritis.

\section{ACKNOWLEDGMENT}

The authors are very much thankful to the Chairman of JB group of Educational Institutions Sri. J. Bhaskar Rao Garu for his help, support and encouragement. The authors are also thankful to him for providing suitable research lab facilities at Bhaskar Pharmacy College, R.R.District, Hyderabad, Andhra Pradesh, India. 


\section{REFERENCES}

1. Agarwal, V., Sharma, PK., Bansal, M. 2011. Chronobiological approach for treatment of rheumatoid arthritis, J. Chronotherapy and Drug Delivery 2, 1-6.

2. Najmuddin, M., Vishal Ashok Patel., Azgar Ali., Shelar, S., Tousif, K. 2010. Development and evaluation of pulsatile drug delivery system of flurbiprofen. Res. J. Pharm. Bio. Chem. Sci. 1, 289-290.

3. Frank Buttgereit. 2011. Chronotherapy with Glucorticoids in Rheumatoid Arthritis. The Rheumatologist, January.

4. Singh, A., Dubey, H., Shukla, I., Singh, D.P. 2012. Pulsatile drug delivery system: an approach of medication according to circadian rhythm. J. App. Pharm. Sci. 02, 166-176.

5. Gothaskar, AV., Joshi, AM., Joshi, NH. 2004. Pulsatile drug delivery system - a review. Drug Del Tech, 4, 1-14. http://www.ijrpbsonline.com/files/38.pdf

6. Abhinetri, V., Hadi, M.A., Rao, A.S. and Sravani V. 2013. Development of a Novel Enteric Coated Extended Release Pellets using Model NSAID Flurbiprofen. Intl. J. Pharm. Sci. Res.. 4, 754-760.

7. Mothilal, M., Swati, PS., Shaik Nelofar., Damodharan, N., Manimaran, V., Lakshmi, KS. 2012. Formulation and evaluation of aceclofenac compression coated tablets for colon drug delivery. Res. J. Pharm. Bio. Chem. Sci. 3,: 10621071. http://www.rjpbcs.com/pdf/2012_3(2)/[123].pdf
8. Kidd, B., Frenzel, W. 1996. A multicenter, randomized, double blind study comparing lornoxicam with diclofenac in osteoarthritis. J. Rheumatol. 23, 1605-1611. http://www. ncbi.nlm.nih.gov/pubmed/8877932

9. Zhang, Y., Zhong, D., Si, D., Guo. Y., Chen, X., Zhou, H. 2005. Lornoxicam pharmacokinetics in relation to cytochrome P450 2C9 genotype. Br. J. Clin. Pharmacol. 59, 14-17.

10. Bansal, A.K. and Deshpande, V. 2013. Development and evaluation of dual cross-linked pulsatile beads for chronotherapy of rheumatoid arthrities. J. Pharm. 1-8.

11. Chikkanna N. and Mayasandra S.S.. 2010. Study the effect of formulation variables in the development of timed-release press-coated tablets by Taguchi design. Nat. Sci. 2, 379-387.

12. Raghavendra Rao, NG., Hadi, M.A., Wahid, M. Munde, M. and Ghurghure, M.S. 2011. Development and evaluation of tablets-filled-capsule system for chronotherapeutic delivery of Montelukast sodium. Int. J. Pharm. Technol. 3, 17041723.

13. Lachman, L., Libermann, H.A. and Kanig, J.L. 1991. The theory and practice of industrial pharmacy. Varghese Publishing House, 3rd ed. pp. 297-301.

14. European Medicines Agency. 2003. "Note for guidance on stability testing: Stability testing of new drug substances and products (CPMP/ICH/2736/99)", August. http://www.scribd. com/doc/34161756/Ich-Guideline-on-Stability. 